\title{
A Novel Sol-Gel Method to Produce the Poly-L-lysine Coated Plate as a Platform for Protein Chips
}

\author{
June Won Hyun, Shi Yong Kim, Sanghee Lee, ${ }^{\ddagger}$ Heonyong Park, ${ }^{\dagger}$ Jacho Pyee, and Sunghoon Kim ${ }^{\ddagger}$ \\ Department of Applied Physics, Danhook Liversin, San 8, Hannan-dong, Fongsan-ku, Seoul 140-7/4, Korea \\ ${ }^{\dagger}$ Department of holecular Biologv. Dankook Lniversin, San 8, Hanhan-dong, Fongsan-ku, Seoul 140-7/4, Korea

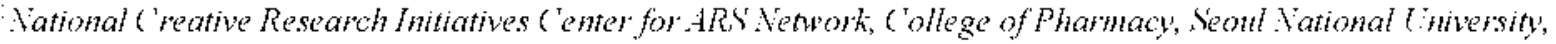 \\ San 56-1. Shillim-dong, Kwanak-ku, Seoul 151-742, Norea \\ Received.Janiav' 10, 2003
}

Key Words : Protein adsomption, Poly-J,-lysine coated glass slide. Protein chip, Sol-gel

The high-throughput methods have been frequently used in the genomic studies to unravel unknown mechanisms for luman diseases and biological events. DNA chips as tools for the high-throughput analysis have recently been developed and are now utilized to identify the expression profile of the full set of genes. ': Now a very few of protein chips have been developed and utilized as a research tool. However the preparation of universal protein chips for multiple purposes is hardly possible to make. because of their unstable three-dimensional structures and strong reactivity: More importantly, active confomations of proteins are easily denatured in harsh experimental conditions. resulting in teclnical difficulties for constructing protein clips. ${ }^{3}$

So far. various approaches have been employed to construct protein-adsorbed platforms. Although polyacry lamide gel pads, polyviny lidene difluoride and nitrocellulose filters have been used as substrates for the adsorption of proteins. these opaque substrates could be inconvenient to detect the adsorbed proteins. Therefore the glass slides have been preferentially employed for the protein microarray display techniques due to their availability for better detection. Aldehyde- and amine-exposed glass slides were used to adhere proteins ${ }^{4.5}$ and a nickel chloride-coated glass slide was also developed to bind the histidine-tagged proteins.

Howerer the sol-gel method has a disadrantage. Since the sol-gel method does not form covalent linkages between chemicals and the glass slide. tight coating resistant to strong acids/bases or organic solvents is hard to be expected. Therefore we have searched for a polymer as a candidate for substances coated on the slide because the polymer coating could be stronger than the small molecule coating due to its different physical properties such as high viscosity and its fibrous form. For the above purposes. a polymer. poly-Llysine, was chosen as a coating material. This polymer has another advantage for adsorbing proteins to the slide. because of possessing a lot of amine groups. The amine groups on the surface of the slide were chemically crosslinked with a variety of proteins. efficiently fabricating the

"Comesponding author. Phone: +82-2-709-2813: l'ax: +82-2-7926082: L-mail: juhyun $a$ dankook ac.kr protein chips.

In order to fabricate a proper platform for the protein clip. we varied the coating conditions and examined the efficiency and level of protein absorption to the slide. The conditions that we varied were the coating amount of polyL-lysine, the spin speed and time. and drying temperature. The protein adsorption was measured using a BAS image analyzer after the slides were incubated consecutively with a cross-linker. 1-ethyl-3-[3-dimethylaminopropyl] carbodiimide hydrochloride (EDC) and a fluorescein isothiocyanate (FITC)-tagged $\mathrm{p}+3$ protein. As showing in Figure 1. the protein adsorption was affected by the spinning time. the amount of poly-L-lysine and the drying temperature. The protein adsorption appears optimal at three second spinuing. $0.2 \mathrm{~mL}$ of poly-L-lysine $(0.16 \mathrm{mg} / \mathrm{mL})$ and $55^{\circ} \mathrm{C}$-drying temperature. The spin speed $(500$ to $3000 \mathrm{rpm})$ had no significant effect on the protein adsorption to the slide (data not shown). To know whether protein binding was specific. we investigated the adsorption propensity for the various amount of the FITC-tagged protein to the slide prepared at the above condition (Figure $1 \mathrm{C}$ ). As increasing the amount of the protein. the detection of adsorbed protein became explicitly higher. implying that the protein adsorption was specific. To exclude the possibility for non-covalent adsorption to the PLL coated slide. we adsorbed the protein to the PLL coated slide pretreated with none or a crosslinker. EDC (Figure ID). The FITC-tagged protein was adsorbed only to the PLL coated slide pretreated with EDC. indicating that the $\mathrm{p}+3$ protein was not physically adsorbed to the PLL coated slide, but covalently linked to amine groups in poly-L-lysine. In addition our previous report suggests that a protein cross-linked to anine groups in the slide through EDC is active.

We then compared our poly-L-lysine-coated slide with other amine-exposed glass slides commercially available for fabricating the protein chips. Interestingly: our slides had higher capability to absorb proteins than the other commercially available slides (Figure IE) and our previous PPEDA coated slide (see reference 7 ). In addition, we also compared the density of amine groups exposed on the slides by detection of FITC using a BAS image analyzer after reacting amine groups directly with FITC. The amine density on our 

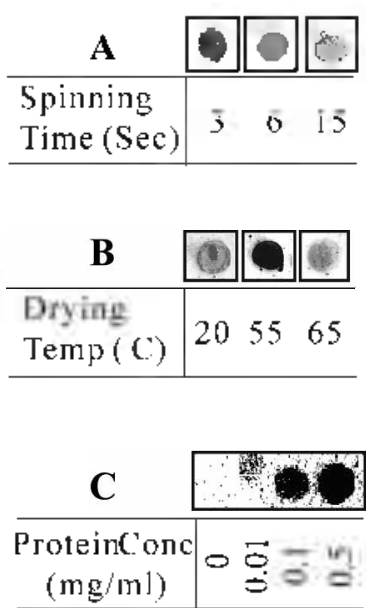
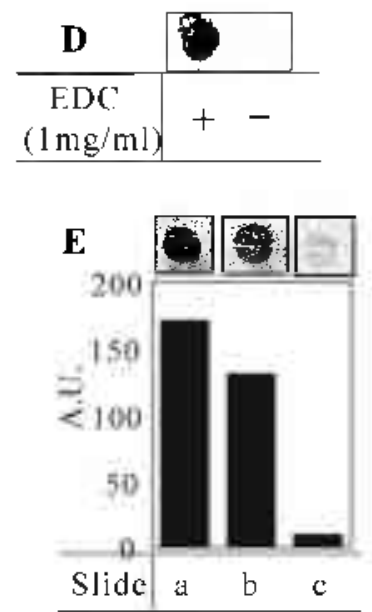

Figure 1. 'The lille-labeled protein appears prodominantly adsorbed to the poly-I.-ly sine coated slide comparing to other topes of amine-exposed slides. The poly-I.-lysine coated slides were prepared for the indicated spinuing time (A) at the indicaled dring temperature (B). Then the slides were cross-linked to the li'l'Clabeled protein as previously described in reterences 6 and 7 . Brietly the I-ethyl-3-[3-dimethylaminopropyl]carbodimide hydrochloride ( $\mathrm{LLCC}$ ) solution ( $1 \mathrm{mg} / \mathrm{mL}$ ) was appliced to the surlace of the poly-L-lysune (PLL)-coated slide and incubated for 10 min at room temperature. The unbound FDC was thoroughy washed with PBS more than tour times. Then, the FITC-labeled pt3 prolein solution $(0.1 \mathrm{mg} / \mathrm{mL})$ was incubaled for $1 \mathrm{~h}$, washed with PBS and dried lor lluorescence detection. The adsorbed protein was detected by the $B \wedge S$ inage analyzer at excitation and emission of 490 and $520 \mathrm{~mm}$, tespectively. The FITC-labeled 04.3 protein was specilically adsorbed in a dose-dependent mamer (C) and in the presence or absence of LDC (D) to the PLL coated slide that was constructed by the above method. Furthermore in panel $\mathrm{F}$, the protein adsorytion for the poly-I,-lysine coated slide was compared with that lor the other trpes of amine-ceposed slides (a: the PLL-coaled glass slide, b: the Arravit slide, and a: the Coming slide).

slides was also highest (data not shown), probably due to plenty of amine groups inherently present in poly-L-lysine.

ln order to elucidate the physical mechanism underlying the capability of the poly-L-lysine slides for absorbing proteins, we then observed the surface of the three different slides using an atomic force microscope (AFM: DI Nanoscope $3 \mathrm{~A}$ ). Interestingly: the surface roughness of the slides was highly related to the protein adsorption to the slides: the poly-L-ly sine coated slide (slide a) appeared most rough and the slide $c$ with less or no protein adsorption showed the smoothest surface (Figure 2). It is likely that the more roughness of the surface provides the higher accessibility for proteins to the surface.

ln summary. constnuction of protein chips for diverse purposes is very difficult to make because proteins are inherently unstable and their functionality is easily disturbed in the process of adsorption. Therefore. a diverse type of protein chips will be constnicted for better utilities of protein chips. The significance of the current works is the supply of a better amine-exposed platform for the fabrication of the protein chips. The excellent protein adsorption of this plat-

(A) D1

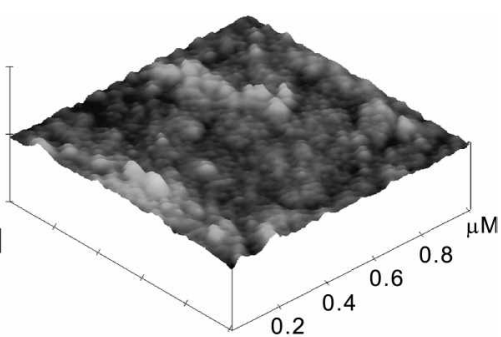

(B) A

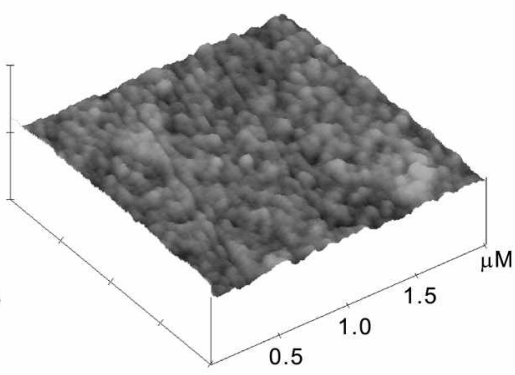

(C) $\mathrm{C}$

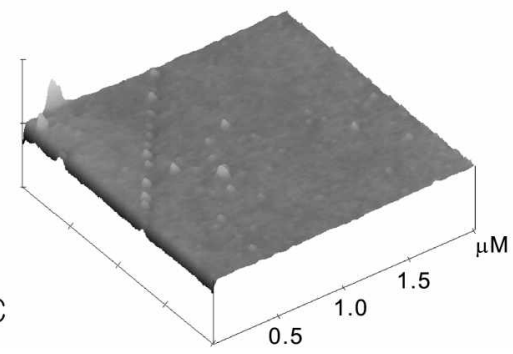

Figure 2. AFM Micrograph for the different types of amineexposed glass slides. a: the PLL-coaled glass slide, b: the Arratit slide, and c: the Coning slide.

form comparing with other types of amine-exposed slides is reflected by more surface roughness providing higher protein accessibility. The sol-gel method presented here. furthermore suggests a model techuique to coat the glass slides with chemicals containing other functional groups for the fabrication of the protein chips.

Acknowledgements. This work was supported by a grant from Ministry of Science and Technology of Korea through Proton Accelerator User Program (No.MI02KS010001$02 \mathrm{~K} 1901-01810$. to J.H.). by a grant from National Creative Research Initiatives of Ministry of Science and Technolog: Korea (to S. K.), and by Korea Research Foundation (to J. P. and H.P.).

\section{References}

1. Ramaswamy. S.: Golib. T. R. J. Clin. Oncol 2002. 20. 1932.

2. Debouck. C.: Goodfellow: P. N. Wat. (Ge'tet. 1999. 2\% 48.

3. Fung. E. T.: Thulasiaman. V: Weinbererer. S. R.: Dalmasso. E. A. Cmin. Opin. Biotechol. 2001. 12.65

4. MacBeath, G.: Scliriber, S. Sicience 2000. 289. 1760.

5. Nicolau, D. V: Taguchi, It:; Taniguchi, H.: Yoshikana, S. Langmuit 1998. If. 1927.

6. Hyun. J. W.: Kim. S. Y.: Lee. S.: Park. H.: Pyee J.: Kim. S. Bull. Korron Chem. Soc. 2002. 23. 1.

7. Kim, J.: Park, H.: Jung. D.: Kim, S. Anal Biochem. 2003, 313. 41. 